Original Article

\title{
A Study on Awareness, Attitude and Myths Regarding Swine Flu Pandemic in Rural Communities of Coastal Karnataka: A Cross- Sectional Study
}

\author{
Vinu E. ${ }^{1}$, Sanjay Kini ${ }^{2}$, Sanjeev Badiger ${ }^{3}$, N. Udaya Kiran ${ }^{4}$ \\ ${ }^{1}$ Postgraduate, ${ }^{2}$ Assistant Professor, ${ }^{3}$ Professor, ${ }^{4}$ Professor and Head, Department of Community M edicine, K.S. Hegde \\ M edical Academy, NITTE University, Deralakatte, Mangalore - 575018.
}

*Corresponding Author : Sanjay Kini, Assistant Professor, Dept. of Community Medicine, K.S. Hegde Medical Academy, NITTE University, Deralakatte, Mangalore-575018. E-mail : sanjaykini2010@gmail.com

Received : : 18.06.2016

Review Completed : 01.01.2017

Accepted

:02.02.2017

Keywords : Awareness, Swine flu, Coastal Karnataka

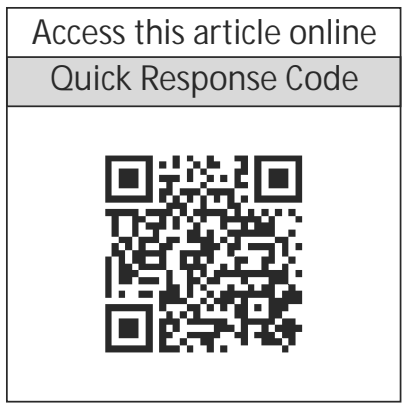

\begin{abstract}
Introduction : Swine flu being a dreadful disease, without an ounce of doubt, has caused a major fear among the common people of India across various strata of the society. In global terms, India was one of the most affected countries in terms of magnitude of cases and deaths of swine flu (influenza A H1N1) during the 2009 influenza pandemic which caused a lot of public hype and panic.
\end{abstract}

Objectives : To study the awareness, attitude and myths regarding swine flu pandemic in a rural community of coastal Karnataka

Methodology : A cross sectional study was conducted in rural field practice area of the department of community medicine of K.SHegde M edical Academy during the year 2015, using a pre-tested semi-structured questionnaire, consisting of details on socio-demographic factors, awareness and attitude about swine flu.

Results : A total of 365 subjects were interviewed using a pretested semi-structured questionnaire. $67.3 \%$ of the subjects were aware about swine flu, tele-media being the major source of information. Among those who were aware about swine flu, 35.3\% of subjects knew about the preventive measures.

Conclusion: There is a need to build strategies to create more awareness about swine flu pandemic through effective mass media which is vital for containing the pandemic.

\section{Introduction}

The novel influenza A/H1N1, which is caused by influenza type $A$ virus is an acute respiratory tract infection and is known as swine flu in layman terms ${ }^{1}$. Coughing, sneezing, or touching contaminated surfaces followed by touching the nose or the mouth are some of the modes of spread of $\mathrm{HIN1}^{2}$. Transmission of the new strain is mostly from human to human; however, eating cooked pork products will not transmit the virus, a myth which is prevalent in rural household ${ }^{3}$. Its symptoms are similar to those of general influenza. Fever, cough, sore throat, body aches, headache, chills, and fatigue are the most common symptoms of Swine flu? ${ }^{2}$.

The 1918 flu pandemic, which was known as Spanish flu, (infected about 500 million people and caused approximately 50 million deaths) was known to be the first documented swine flu pandemic across the globe ${ }^{4}$. An outbreak of novel influenza A/H1N1 infection occurred in Mexico at the end of March 2009, followed by ongoing spread to all over the world in a short period ${ }^{1}$. The World Health Organization (WHO), on 11 June 2009, raised its pandemic alert to the highest level, phase 6 , meaning that, the A/H1N1 flu had spread in more than two continents ${ }^{4}$. It had caused over 18,172 deaths in more than 214 countries and overseas territories or communities, around June $2010^{5}$.

India was no exception with regards to the mortality due swine flu. Deaths were reported in metropolitan cities such as M umbai, Pune and Bangalore ${ }^{6}$. Given the seriousness of the situation and lack of any specific vaccine against swine 
flu, mitigation measures in India have so far focused on identifying, treating, and isolating people who have the disease and educating the public about the steps that individuals can take to reduce the risk of transmission.

The knowledge, attitudes, and practices of people regarding swine flu form a cornerstone in prevention of the virus spread and outbreak. Keeping all these facts in view the study was designed to assess the awareness, attitude and myths regarding Swine flu among the people of coastal Karnataka.

\section{Methodology}

A cross sectional study was conducted in rural field practice area of the department of Community M edicine, K.SHegde M edical Academy during the year 2015. Sample size for the study was calculated based on a previous study conducted by Shilpa K et al' in Belgaum where awareness of swine flu was found to be $73.6 \%$. By applying the formula, Prevalence $=4 \mathrm{PQ} / \mathrm{L}^{2}$, where $\mathrm{P}=$ Prevalence of previous study, $Q=1-P, L=$ precision of $5 \%$, and considering a nonresponse rate of $20 \%$, a sample size of 365 was calculated. The places of study were 6 villages namely Bailur, Nitte, Hejamadi, Mulki, Sasihitlu, Natekal, Kadri, Farangipete, Bengre and Talipady which constituted the rural field practice areas of the department of Community M edicine, KS Hegde Medical Academy, Mangalore. The study included households that have been dwelling in the respective place at least 6 months prior to the time of interview. Required numbers of subjects were selected by stratified sampling with proportional allocation. Stratification was based on the locality. The investigators went to the centre of the locality and the nearest house was taken as the first house for the study in that locality. The investigators then moved in one particular direction and covered all the houses till they achieved the required sample for the locality. The head of the house or the eldest responsible member of the house present at the time of visit was interviewed. A pretested semi-structured questionnaire was administered to the subjects after obtaining their informed consent. The questionnaire consisted data on socio-demographic details and details on their awareness and perceptions towards H1N1 influenza. Socio-economic status was assessed using modified BG Prasad scale ${ }^{8}$. Data obtained were recorded in Microsoft excel and then analysed using Statistical Package for Social Sciences (SPSS) version 16. Categorical data was expressed as percentages and proportions. Ethical clearance for the study was obtained from institutional ethics committee of KSHegde M edical Academy.

\section{Results}

Out of the 365 people interviewed 190 were males and 175 were females. Most of the study participants were educated up-to primary school about $34 \%$. Most of the study subjects (23.6\%) were in the age group of more than 61 years. 194 (53.2\%) families out of 365 belong to nuclear type of family which constituted the majority. About 136 (37.3) were unskilled labourers by occupation which formed a major proportion of the occupational category. Only 244 people responded about their income which was required to calculate socio-economic status according to modified BG Prasad scale. It was found that most of them (35.2\%) belonged to class I. Table 1 depicts the sociodemographic profile of study subjects

Table 1 : Socio-demographic profile of study subjects ( $N=365$ )

\begin{tabular}{|l|l|l|l|}
\hline Gender & Number (\%) & $\begin{array}{l}\text { Age distribution } \\
\text { (Yrs) }\end{array}$ & Number (\%) \\
\hline Male & $190(52.1)$ & $<=30$ & $73(20.0)$ \\
\hline Female & $175(47.9)$ & $31-40$ & $71(19.5)$ \\
\hline Educational status & Number (\%) & $41-50$ & $60(16.4)$ \\
\hline Illiterate & $20(5.5)$ & $51-60$ & $75(20.5)$ \\
\hline Primary school & $124(34.0)$ & $>=61$ & $86(23.6)$ \\
\hline Secondary school & $113(31.0)$ & Type of Family & Number (\%) \\
\hline PUC & $57(15.5)$ & Nuclear & $194(53.2)$ \\
\hline Graduate & $48(13.2)$ & Joint & $123(33.7)$ \\
\hline $\begin{array}{l}\text { Post graduate } \\
\text { and above }\end{array}$ & $3(0.8)$ & $\begin{array}{l}\text { Three } \\
\text { Generation }\end{array}$ & $48(13.2)$ \\
\hline Occupation & Number (\%) & Address & Number (\%) \\
\hline Professional & $8(2.2)$ & Bailur & $30(8.2)$ \\
\hline White Collar & $6(1.6)$ & Nitte & $59(16.2)$ \\
\hline Skilled & $64(17.5)$ & Hejamadi & $23(6.3)$ \\
\hline Unskilled & $136(37.3)$ & Mulki & $35(9.6)$ \\
\hline Student & $27(7.4)$ & Sasihitlu & $47(12.9)$ \\
\hline Housewife & $105(28.8)$ & Natekal & $45(12.3)$ \\
\hline Retired & $19(5.2)$ & Kadri & $30(8.2)$ \\
\hline
\end{tabular}




\begin{tabular}{|l|l|l|l|}
\hline $\begin{array}{l}\text { Socio-economic } \\
\text { status* }\end{array}$ & Number (\%) & Farangipet & $44(12.1)$ \\
\hline Class I & $86(35.2)$ & Bengre & $24(6.6)$ \\
\hline Class II & $48(19.7)$ & Talipady & $28(7.7)$ \\
\hline Class III & $45(18.4)$ & & \\
\hline Class IV & $65(26.6)$ & & \\
\hline
\end{tabular}

* Note that Socio-economic status was calculated for 244 subjects

When enquired about whether they have heard of swine flu $246(67.3 \%)$ replied positive. So further questions were asked to those who had ever heard of swine flu. Out of those 246 people, the major source of information about swine flu was tele-media. Multiple responses to the options were allowed for the study subjects with regards to source of information. Fig 1 depicts the source of information on swine flu among those people who had heard of it.

Fig 1: Source of information about swine flu among study subjects $(N=246)$

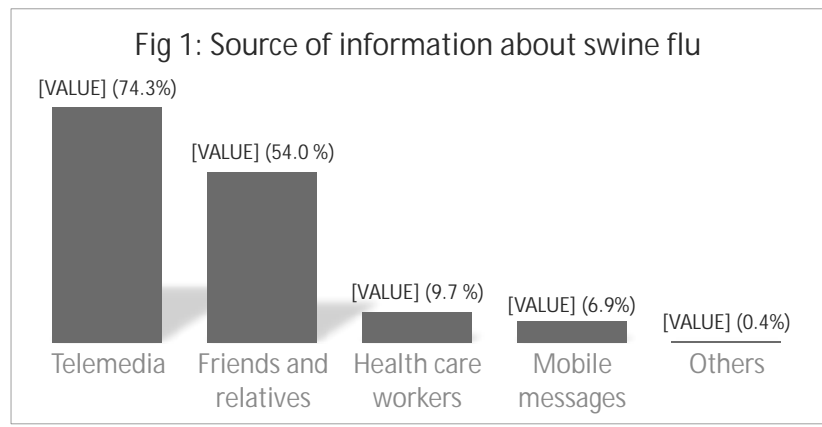

* Note that multiple responses to the options were allowed to the subjects in the abovefig

$150(60.9 \%)$ subjects out of the total 246 who have heard of swine flu knew the symptoms of swine flu. Out of them, most of the people knew that fever will be the main symptom. Multiple responses to the options were allowed with regards to the knowledge of study subjects about symptoms of swine flu. Table 2 depicts the knowledge of the study subjects with regards to the symptoms of swine flu.

Table 2 : Knowledge of the study subjects with regards to symptoms of swineflu

$(\mathrm{N}=246)$

\begin{tabular}{|l|l|}
\hline Symptoms & Number (\%) \\
\hline Body ache & $21(8.5)$ \\
\hline Cold & $61(24.7)$ \\
\hline Cough & $45(18.2)$ \\
\hline Fever & $75(30.4)$ \\
\hline Head ache & $9(3.6)$ \\
\hline
\end{tabular}

\begin{tabular}{|l|l|}
\hline Symptoms & Number (\%) \\
\hline Sore throat & $11(4.4)$ \\
\hline Vomiting & $4(1.6)$ \\
\hline Weakness & $10(4.0)$ \\
\hline Rashes & $3(1.2)$ \\
\hline Weight loss & $2(0.8)$ \\
\hline Others & $3(1.2)$ \\
\hline
\end{tabular}

* Note that multiple responses to the options were allowed to the subjects in the above table

Regarding modes of spread majority, that is 120 (48.7\%) answered that it was through cough and sneeze. Multiple responses to the options were allowed with regards to the knowledge among the study subjects about the modes of spread of swine flu. The knowledge of study subjects regarding the modes of spread of swine flu is depicted in Table 3.

Table 3 : Knowledge of study subjects about the modes of spread of swine flu

$(\mathrm{N}=246)$

\begin{tabular}{|l|c|}
\hline Modes of spread & Number (\%) \\
\hline Cough and sneeze & $120(48.7)$ \\
\hline M osquito bite & $32(13.0)$ \\
\hline Contaminated food and water & $49(19.9)$ \\
\hline Sexual contact & $5(2.0)$ \\
\hline Curse of God & $1(0.4)$ \\
\hline Consuming pork & $42(17.0)$ \\
\hline Don't know & $64(26.0)$ \\
\hline
\end{tabular}

* Note that multiple responses to the options were allowed to the subjects in the above table

Out of the total 246, 170 (69.1\%) told that they are scared of swine flu. Of the 170 who were scared of swine flu, 92 (54.1\%) said they are scared because it is a deadly disease, $59(34.7 \%)$ said anyone can be affected, $41(24.1 \%)$ said there is no treatment and $3(1.7 \%)$ people said that there is no vaccine. Multiple responses to the options were allowed with regards to their attitude as to why they were scared of swine flu. When enquired where will they go if they get symptoms of swine flu, 162 (65.8\%) said that they would go to government hospital, $62(25.2 \%)$ said that they would go to private hospital, 10 (4.0\%) said that they would go to family physicians and the rest 12 (4.8\%) said that they would go to traditional healers. When enquired whether there is treatment for swine flu 81 (32.9\%) people said that there is treatment, 59 (23.9\%) people said that there is no treatment and the rest of them said that they do not know. 
Only 87 (35.3\%) people were aware about the preventive measures of swine flu. Multiple responses to the options were allowed with regards to the knowledge among the study subjects about the preventive measures against swine flu. The knowledge about the preventive measures of swine flu among the study subjects is depicted in table 4.

Table 4: Knowledge regarding preventive measures against swine flu $(\mathrm{N}=87)$

\begin{tabular}{|l|l|}
\hline Preventive measures against swine flu & Number (\%) \\
\hline Hand washing & $24(27.6)$ \\
\hline Using face masks & $18(20.6)$ \\
\hline $\begin{array}{l}\text { Avoid touching eyes, nose, mouth with } \\
\text { unwashed hands }\end{array}$ & $26(29.8)$ \\
\hline Use disposable tissue to wipe nose \& mouth & $12(13.7)$ \\
\hline Avoid crowded places & $7(8.0)$ \\
\hline
\end{tabular}

* Note that multiple responses to the options were allowed to the subjects in the abovetable

When enquired whether there is vaccination against swine flu $49(19.9 \%)$ people said that there is vaccination, 66 $(26.8 \%)$ said that there is no vaccination and the rest said that they do not know. Regarding their willingness to get vaccinated $216(87.8 \%)$ of people were willing to get vaccinated while the rest of them were not willing.

\section{Discussion}

In our study $67.3 \%$ of the study subjects had heard of swine flu, which was lesser when compared to other studies, 10:13. The reason for this may be due to lack of awareness and ignorance regarding health issues in our study population due to rural background. Present study had more of male participants, which was similar to many other Indian studies $^{3,6,10,12}$. While the number of female participants were found to be more in studies done outside India like the one study conducted in Kuala Lumpur, Malaysia by Latiff et al ${ }^{14}$ and a study conducted by Lin et a ${ }^{15}$ in China. Tele-media was the most common source of information in our study which was similar to many other studies ${ }^{3,7,11,13,16,17}$. It was seen that in our study the source of information obtained through health care workers was very little, the reason could be that they were not trained up to the expected standards and their knowledge regarding the disease was dismal. Hence we recommend that they should take this opportunity and maximize their efforts in providing health education as they are nearer to the community at large. There is a need to provide regular training program which should be designed and implemented with the aim of capacity building of the peripheral health workers, so as to make them enriched with knowledge and to update their skills, thus enabling them to teach the various advancements pertaining to swineflu.

In our study it was observed that fever was the most common symptom known to majority of the participants which was similar to that observed in other studies ${ }^{7,10,12,13}$. A cause of concern depicting a serious lack of knowledge was highlighted by the fact that $17 \%$ of the study subjects $(\mathrm{N}=246$ ) thought that swine flu can be spread by eating pork. Such a misconception was seen only among $2.7 \%$ of the study population in the study done by Shilpa Ket al ${ }^{7}$, the reason could be that it was done in Urban population. But studies done elsewhere like the one done by Singh S et $\mathrm{al}^{10}$ in Patiala showed that such a misconception existed among $40.6 \%$ of study population which is more than that found in our study. In our study $2 \%$ of individuals ( $N=246$ ) had the misconception that swine flu can be transmitted by sexual contact. Such a myth existed in higher proportion (43\%) among the subjects in the study conducted by Balkhy HH et al ${ }^{16}$ in Saudi Arabia.

Use of face mask as a preventive measure was known to only $20.6 \%$ of population ( $N=246$ ) in our study, which is similar to the result found in the study done by Farhat et $\mathrm{al}^{13}$. While other studies like the ones done by Shilpa K et al ${ }^{7}$ and Singh et a ${ }^{10}$ showed higher results which were $81.5 \%$ and $56 \%$ respectively. Hand washing as an effective preventive measure was known to $27.6 \%$ of study subjects $(\mathrm{N}=246)$, which is lesser when compared to the study conducted by Shilpa K et al ${ }^{7}$ where it was $37 \%$. A very high proportion of study subjects knew hand washing as an effective preventive measure in a study conducted by Rubin GJ et al ${ }^{18}$. This may be because of lack of tele-media facilities in rural areas as compared to urban areas.

\section{Conclusion}

Knowledge regarding the swine flu pandemic was not 
satisfactory among the study participants. What is vital for containing the pandemic is an effective mass media communication directed towards creating awareness among common folks. The knowledge and attitudes regarding swine flu pandemic was investigated in this study, which may act as a scientific support to assist health sector authorities in developing strategies and campaigns

\section{References}

1. Girard MP, Tam JS, Assossou OM, Kieny MP. The 2009 A (H1N1) influenza virus pandemic: A review. Vaccine 2010; 28: 4895-902.

2. $2009 \mathrm{H} 1 \mathrm{~N} 1 \mathrm{Flu}$ ("Swine Flu") and You. Centers for Disease Control and Prevention, Atlanta. Feb 10, 2010. Available from URLhttp:// www.cdc.gov/h1n1flu/qa.htm\#(Accessed on 16-09-2016)

3. Praveen Kumar BA, Karnum S, Kumar SY, Ugargol AR, Naik VA, M allapur MD. Pandemic influenza A H1N1 awareness in a rural community of North Karnataka, India. TropJ M ed Res 2015;18:74-9

4. World Health Organization (WHO). Pandemic (H1N1) 2009 - Update. Disease Outbreak News (WHO); 2010 M ay 14.

5. Novel Swine-Origin Influenza A (H1N1) Virus Investigation Team, Dawood FS, Jain S, Finelli L, Shaw M W, Lindstrom S, et al. Emergence of a novel swine-origin influenza A (H1N1) virus in humans. N Engl J M ed 2009; 360:2605-15

6. Kumar N, Sood S, Singh M , Kumar M , M akkar B, Singh M . Knowledge of swine flu among Health Care workers and General Population of Haryana India during 2009 pandemic. Australasian Medical Journal 2010; 3(9): 614-617

7. Shilpa K, Praveen Kumar BA, Kumar SY, Ugargol AR, Naik VA, M allapur MD. A study on awareness regarding swine flu (influenza A H1N1) pandemic in an urban community of Karnataka. Med J DY Patil Univ 2014; 7:732-7

8. Mangal A, Kumar V, Panesar S, Talwar R, Raut D, Singh S. Updated BG Prasad socioeconomic classification, 2014: A commentary. Indian J Public Health 2015;59:42-4

9. Kamate SK, Agrawal A, Chaudhary H, Singh K, M ishra P, Asawa K. Public knowledge, attitude and behavioural changes in an Indian population during the Influenza A (H1N1) outbreak. J Infect Dev Ctries 2009;4:714.

10. Singh S, Kaur P, Singh G. Study to assess the awareness, perception and myths regarding swine flu among educated common public in Patiala District. IntJ Res Dev Health 2013; 12:54-60. of health education to prevent transmission of H1N1 influenza and related pandemics.

Some of the existing lacunae in the health sector that need immediate attention are lack of laboratory facilities, pooling of cases, lack of manpower, vaccine, and investigation as well as a poor health information management system.

11. Rathi S, Gandhi H, Francis M. Knowledge and awareness about H1N1 flu in urban adult population of Vadodara, India. Available from Urlhttp://www.academia.edu/2848942/Knowledge and Awareness a bout_H1N1_Flu_in_Urban_Adult_Population_of_Vadodara_India. [Accessed on 16-09-2016].

12. Chaudhary V, Singh RK, Agrawal VK, Agarwal A, Kumar R, Sharma M. Awareness, perception and myths towards swine flu in school children of Bareilly, Uttar Pradesh. Indian J Public Health 2010; 54:161-4.

13. Farahat T, Al-Kot M, Al-Fath AO, Noh A, Diab N. Promotion of knowledge, attitude and practice towards swine flu A/H1N1; An intervention study on secondary school children of Menofia Governorate, Egypt. Menofia M ed J 2010; 23:83-94

14. Latiff LA, Parhizkar S, Zainuddin H, Chun GM, Rahiman MA, Ramli NL, et al. Pandemic influenza A (H1N1) and its prevention: A cross sectional study on patients' knowledge, attitude and practice among patients attending primary health care clinic in Kuala Lumpur, Malaysia. GlobJ Health Sci 2012; 4:95-102.

15. Lin Y, Huang L, Nie S, Liu Z, Yu H, Yan W, et al. Knowledge, attitudes and practices (KAP) related to the pandemic (H1N1) 2009 among Chinese general population: A telephone survey. BM C Infect Dis 2011; 11:128.

16. Balkhy HH, Abolfotouh M A, Al-Hathlool RH, Al-Jumah M A. Awareness, attitudes, and practices related to the swine influenza pandemic among the Saudi public. BM CInfect Dis 2010; 10:42.

17. Verma SK, Gupta S, Yadav R, Singh S. Awareness About Swine Flu and Perception Regarding its Prevention Among M edical Students During Current Outbreak in Jhansi. Indian Journal of Applied Research 2015; 5(7): 224-226.

18. Rubin GJ, Potts HW, Michie S. The impact of communications about swine flu (influenza A H1N1v) on public responses to the outbreak: Results from 36 national telephone surveys in the UK. Health Technol Assess 2010; 14:183-266. 